\title{
Consumos e Digestibilidades Totais e Parciais de Carboidratos Totais, Fibra em Detergente Neutro e Carboidratos Não-Fibrosos em Novilhos Submetidos a Três Níveis de Ingestão e Duas Metodologias de Coleta de Digestas Abomasal e Omasal ${ }^{1}$
}

\section{Maria Ignez Leãoㄹ, Sebastião de Campos Valadares Filho², Luciana Navajas Rennó ${ }^{3}$, Paulo Roberto Cecon $^{2}$, José Augusto Gomes Azevedo ${ }^{4}$, Lúcio Carlos Gonçalves ${ }^{5}$, Rilene Ferreira Diniz Valadares ${ }^{6}$}

RESUMO - Seis novilhos $1 / 2$ sangue Holandês-Zebu castrados, fistulados no rúmen e no abomaso, foram distribuídos em dois quadrados latinos $3 \times 3$ (três animais, três níveis de oferta - 1,5; 2,0 e 2,5\% PV e três períodos) para determinar os consumos e as digestibilidades totais e parciais dos carboidratos totais ( $\mathrm{CHO}$ ), da fibra em detergente neutro (FDN) e dos carboidratos não-fibrosos (CNF). As digestibilidades foram determinadas com óxido crômico. Os consumos de CHO, FDN, CNF e NDT (kg/dia) e de CHO, FDN e CNF (\% do peso vivo - PV) aumentaram linearmente com os níveis de oferta. O teste de identidade de modelos, realizado para as equações de regressão para as digestibilidades total, ruminal e intestinais dos $\mathrm{CHO}$, em função dos níveis de oferta, indicou não existir diferenças entre as metodologias de coleta. As digestibilidades total, ruminal e intestinais dos $\mathrm{CHO}$ não foram influenciadas pelos tratamentos. A digestibilidade total da FDN diminuiu linearmente com o aumento dos níveis de oferta, enquanto as digestões ruminal e intestinais da FDN não foram influenciadas pelos tratamentos. Não foi observado efeito dos níveis de oferta para as digestibilidades totais dos CNF. Utilizando a metodologia de coleta de digesta no omaso, foi observado aumento linear da digestibilidade ruminal dos CNF. Quando foi usada a coleta no abomaso, não houve efeito do aumento do consumo sobre a digestão ruminal dos CNF. A coleta de digesta abomasal pode ser substituída pela coleta de digesta omasal, via fístula ruminal. A coleta de digesta omasalé vantajosa, tornando o estudo de digestão parcial um processo menos invasivo.

Palavras-chave: coleta de digesta omasal, consumo, digestibilidade, níveis de ingestão, novilhos

\section{Intake and Total and Partial Digestibility of Total Carbohydrates, Neutral Detergent Fiber and Nonfiber Carbohydrates in Steers under Three Ingestion regimes and Two Method of Digesta Collections: Abomasal and Omasal}

\begin{abstract}
Six half-bred $1 / 2$ Holstein-Zebu steers, fistulated in the rumen and abomasum, were randomly assigned to two 3 x3 Latin squares (animal, ingestion regime - 1.5, 2.0 and 2.5\% LW and period) to determine the intake and total and partial digestibility of total carbohydrates (CHO), neutral detergent fiber (NDF) and non fiber carbohydrates (NFC). Chromic oxide was used as a marker to determine the digestibilities. Animals were fed diet with $60 \%$ Tifton- 85 bermudagrass (Cynodon spp.) hay and $40 \%$ concentrate mixture (corn starch, wheat middling, soybean meal, urea and minerals), were used. Intakes CHO, NDF, NFC and TDN (kg/day, \%LW) linearly increased with the ingestion regimes. The identity model test, used to estimate the regression equations for the total, ruminal and intestinal digestibilities of $\mathrm{CHO}$, in function of the ingestion regime, showed no differences among collection methods. Total, ruminal and intestinal carbohydrates digestibilities were not affected by the treatments. Neutral detergent fiber total digestibility linearly decreased as the ingestion regime increased, while NDF ruminal and intestinal digestibilities were not affected by the treatments. No effect of ingestion regime was observed for the NFC total digestibilities. A linear increase of NFC ruminal digestibility was observed by using the omasal method of digesta collection. When the abomasal method of digesta collection was used, no effect of increased intake on the NFC ruminal digestibility was observed. Abomasal method of digesta collection could be replaced by omasal method of digesta collection, by ruminal fistula. Omasal method of Digesta collection is an efficient method, becoming the study of partial digestion a less invasive process.
\end{abstract}

Key Words: omasum digesta collection, intake, digestibility, ingestion levels, steers

\footnotetext{
${ }^{1}$ Parte da tese de Doutorado apresentada à UFMG.

2 Professor do DZO/UFV (mileao@ufv.br).

3 Professora da UNIPAC - Juiz de Fora.

4 Professor da UESC.

5 Professor da UFMG.

6 Professor do DVT/UFV.
} 


\section{Introdução}

Consumo voluntário é definido por Forbes (1995) como a quantidade de alimento ingerido por um animal ou grupo de animais em determinado tempo, com livre acesso ao alimento. Se o consumo voluntário é baixo, provavelmente a taxa de produção diminui, fazendo com que as exigências de mantença sejam oriundas de alta proporção da energia metabolizável do alimento e, como conseqüência, de baixa conversão alimentar. Se o consumo for alto, pode ocorrer excesso de depósito de gordura. Então, a dieta deve ser formulada de acordo com o nível de produção, verificando a disponibilidade, o valor nutritivo e os custos dos alimentos.

O consumo de matéria seca (MS) é função da duração do período e da freqüência de alimentação, determinados pelo animal e por fatores dietéticos que afetam a fome e a saciedade. Muitas pesquisas sobre comportamento alimentar de ruminantes têm evidenciado as características dietéticas que afetam a saciedade, que determinam a duração do período e a freqüência de alimentação (Allen, 2000).

Existe uma relação positiva entre a digestibilidade das forragens e o nível de consumo, em razão da limitação física. A elevação da taxa de degradação e/ ou o fluxo de digesta do rúmen aumentam o consumo. Quando se fornecem aos ruminantes dietas com alto teor de energia, que são digeridas rapidamente, este limite físico não é atingido e o animal controla o consumo para satisfazer suas exigências em energia. Para atingir o nível requerido de produção, é necessária a suplementação da forragem com concentrado, mas este deprime o consumo, o que varia com o nível de concentrado e a qualidade da forragem e do concentrado (Forbes, 1995).

O consumo de MS apresentou aumentos lineares quando as concentrações de fibra em detergente neutro $(\mathrm{FDN})$ foram reduzidas por incremento nas proporções de concentrado nas dietas (Berchielli et al., 1994). As concentrações de FDN das dietas interferem na digestibilidade dos alimentos.

Em novilhos Hereford submetidos a dois níveis de consumo (9,1 e 6,1 $\mathrm{kg}$ de MS/dia), as digestibilidades ruminais aparentes de matéria orgânica (MO) e FDN e a digestibilidade total da FDN foram mais baixas nos animais submetidos a altos níveis de consumo em relação aos baixos níveis: $41,3 \times 44,3 \% ; 56,0 \times 60,2 \%$ e $64,3 \times 68,7 \%$, respectivamente (Firkins et al., 1986b).
A análise química dos alimentos é a primeira etapa em sua avaliação, entretanto, é necessário que se conheça a quantidade de nutriente suficiente para cada animal, o que é possível com a determinação da digestibilidade dos nutrientes. A digestibilidade do alimento, basicamente, é a sua capacidade (expressa pelo coeficiente de digestibilidade) de permitir ao animal o uso de nutrientes em maior ou menor escala.

Os alimentos que chegam ao rúmen passam por dois mecanismos que determinam seu aproveitamento no trato gastrintestinal: são fermentados ou passam em direção ao retículo. A fermentação é característica do alimento, enquanto a passagem está relacionada ao consumo, processamento e tipo de alimento consumido (proporção volumoso:concentrado) e influi de modo extensivo na disponibilidade dos nutrientes para o animal, além de produzir efeitos sobre o balanço dos produtos de fermentação ruminal (Russell et al., 1992).

A taxa de passagem da digesta pelo rúmen tem como fatores críticos o tamanho da partícula e sua gravidade específica. Ingestão de alimentos, tamanho de partículas, densidade e tipo de alimento consumido são fatores que regulam a passagem da digesta ao longo do trato digestivo (Sniffen et al., 1992).

De acordo com Forbes (1995), digestibilidade é o produto do tempo de retenção no rúmen pelas características de degradação do alimento. As partículas maiores dos alimentos permanecem por mais tempo no rúmen, tornando-o digerível em sua máxima extensão, ou seja, seu potencial de digestibilidade. No entanto, fatores como níveis de alimentação e capacidade do rúmen causam variações no tempo de permanência do alimento neste compartimento e, portanto, em sua digestibilidade.

A digestibilidade de dietas para vacas de leite é reduzida com o aumento da ingestão de alimentos (Tyrrel \& Moe, 1975). A taxa de redução na digestibilidade, associada ao nível de ingestão, está relacionada à digestão da dieta fornecida em nível de mantença. Dietas com alta digestibilidade em nível de mantença apresentaram maior taxa de redução com alimentação ad libitum em relação à baixa digestibilidade (NRC, 2001). O NRC $(1985,1989)$ adotou redução constante de 4\% no teor de NDT para cada aumento no consumo de uma vez a mantença para ajustar os valores de energia, considerando que a redução máxima no teor de NDT seria de $8 \%$ para um consumo de três vezes o nível de energia de mantença. A partir dessa relação, o NRC considerou 
que uma dieta contendo $75 \%$ de nutrientes digestíveis totais (NDT) de mantença na MS teria seu teor de NDT reduzido para $67 \%$, quando o consumo de energia fosse de três vezes a mantença. As diferenças nas taxas de redução na digestibilidade, geralmente, são mínimas para dietas contendo teor de NDT para mantença menor ou igual a $60 \%$ (NRC, 2001).

A complexidade da digestão nos ruminantes apresenta desafios para a quantificação dos processos digestivos e absortivos, objetivando maiores conhecimentos da fisiologia digestiva para a melhoria do arraçoamento destes animais. Desse modo, inúmeras técnicas têm sido desenvolvidas para a determinação do fluxo de digesta nos diferentes segmentos do trato digestivo, destacando-se as fistulações de rúmen e abomaso entre os nutricionistas brasileiros. Nos animais fistulados no rúmen, a digesta é coletada para estudos de parâmetros ruminais, enquanto o abomaso, principalmente para determinação das digestibilidades parciais dos nutrientes.

Segundo Titgemeyer (1997), a técnica mais utilizada na determinação do fluxo de digesta do rúmen é a implantação de cânula em T no abomaso ou duodeno e, segundo Ahvenjärvi (2000), são poucos os trabalhos existentes na literatura em que se determina o fluxo de digesta sem implantação de cânula pósruminal. Técnica para coleta de digesta omasal para implantação de uma cânula reentrante omasoabomasal em ovinos foi publicada por Ash (1962). Punia et al. (1988) obtiveram amostras de digesta ruminal através do orifício retículo omasal via fístula ruminal, succionando a digesta com o uso de uma bomba a vácuo.

As taxas de desaparecimento de ácidos graxos e o fluxo de fluidos pelo abomaso de bovinos foram medidos por Rupp et al. (1994), usando uma técnica de canulação omasal. Um processo de amostragem de coleta omasal foi desenvolvido por Huhtanen et al. (1997), que mantiveram o dispositivo de coleta inserido dentro do omaso por 21 dias (período de coleta).

A coleta de digesta omasal apresenta maiores vantagens dem relação à realizada no abomaso ou no duodeno, sobretudo por ser uma técnica menos invasiva.

Neste trabalho, objetivou-se determinar os consumos e as digestibilidades totais e parciais dos carboidratos totais $(\mathrm{CHO})$, da fibra em detergente neutro (FDN) e dos carboidratos não-fibrosos (CNF), em novilhos submetidos a três níveis de ingestão (ofertas de 1,5; 2,0 e 2,5\% PV) e a duas metodologias de coletas de digestas: abomasal e omasal.

\section{Material e Métodos}

O experimento foi conduzido no Departamento de Zootecnia do Centro de Ciências Agrárias da Universidade Federal de Viçosa, em Viçosa, MG, Brasil.

Foram utilizados seis novilhos $1 / 2$ sangue Holandês-Zebu, castrados, fistulados no rúmen e abomaso, com peso vivo médio inicial de $357,3 \mathrm{~kg}$, distribuídos em dois quadrados latinos $3 \times 3$, sendo três animais, três níveis de consumo (ofertas de 1,5; 2,0 e $2,5 \%$ peso vivo - PV em MS) e três períodos experimentais.

Os animais foram mantidos em baias individuais de alvenaria $(3 \times 3 \mathrm{~m})$, com pisos recobertos de borracha, cobertas e adaptadas com bebedouros automáticos e comedouros.

Os animais foram receberam uma dieta constituída de feno de capim-Tifton-85 (Cynodon spp.) e mistura concentrada (fubá de milho, farelo de trigo, farelo de soja, uréia e minerais), nas proporções de 60:40, formulada de acordo com o NRC (1996). As proporções dos ingredientes no concentrado estão na Tabela 1 e a composição química do concentrado, do feno e da ração total, na Tabela 2 .

Cada um dos três períodos experimentais teve duração de 19 dias, sendo os sete iniciais para adaptação dos animais, seis para coleta de digesta abomasal e de fezes e seis para coleta de digesta omasal e de fezes.

A ração total foi fornecida uma única vez ao dia, às 7h30. A quantidade de ração para os animais submetidos à oferta de $2,5 \%$ do PV foi calculada de modo a permitir 5 a $10 \%$ de sobras. Amostras de feno e de concentrado foram coletadas no início do experimento e imediatamente preparadas para posteriores análises laboratoriais. As sobras foram recolhidas todos os dias, antes de se distribuir a ração, e preparadas amostras compostas por animal em cada período. Além das sobras, foram recolhidas e feitas amostras compostas do feno e concentrado utilizados em cada período.

Para determinação das digestibilidades, utilizou-se o óxido crômico, introduzido no rúmen via fístula. A quantidade administrada foi de $15 \mathrm{~g}$, sempre quatro horas após o fornecimento da ração, a partir do $3^{\circ}$ dia de adaptação até o último dia da coleta de digesta omasal.

As coletas de digesta de abomaso e de fezes foram realizadas em intervalos de 26 horas, inciando-se às 8 horas e, em seguida, às 10, 12, 14, 16 e $18 \mathrm{~h}$, 
Tabela 1 - Composição percentual dos ingredientes utilizados no concentrado, expressa na base da matéria natural

Table 1 - Percent composition of feedstuffs used in the concentrate (as fed basis)

\begin{tabular}{lc}
\hline $\begin{array}{l}\text { Ingrediente } \\
\text { Feedstuff }\end{array}$ & $\begin{array}{c}\text { Concentrado } \\
\text { Concentrate }\end{array}$ \\
\hline $\begin{array}{l}\text { Fubá de milho } \\
\text { Corn starch }\end{array}$ & 48,61 \\
$\begin{array}{l}\text { Farelo de soja } \\
\text { Soybean meal }\end{array}$ & 19,40 \\
$\begin{array}{l}\text { Farelo de trigo } \\
\text { Wheat middling }\end{array}$ & 30,00 \\
Uréia & 0,92 \\
$\begin{array}{l}\text { Urea } \\
\text { Sulfato de amônia }\end{array}$ & 0,10 \\
$\begin{array}{l}\text { Ammonia sulfate } \\
\text { Fosfato bicálcico } \\
\text { Dicalcium phosphate }\end{array}$ & 0,50 \\
$\begin{array}{l}\text { Sal comum } \\
\text { Salt }\end{array}$ & 0,46 \\
$\begin{array}{l}\text { Microminerais }{ }^{2} \\
\text { Minerals }\end{array}$ & 0,04 \\
\hline $\begin{array}{l}1 \text { Composição percentual: sulfato de zinco - 0,018, sulfato de } \\
\text { cobre - 0,015, sulfato de cobalto - 0,001, selenito de sódio - } \\
\text { 0,001, iodato de potássio - 0,001. }\end{array}$ & \\
${ }^{1}$ Percent composition: zinc sulfate, .018; copper sulfate, .015, cobalt \\
sulfate, .001; sodium selenite, .001; potassium iodate, .001.
\end{tabular}

Tabela 2 - Teores de matéria seca (MS), matéria orgânica $(\mathrm{MO})$, proteína bruta (PB), extrato etéreo $(E E)$, carboidratos totais $(\mathrm{CHO})$, fibra detergente neutro (FDN) e carboidratos não fibrosos (CNF) do concentrado, feno e ração

Table 2 - Contents of dry matter (DM), organic matter (OM), crude protein $(C P)$, ether extract $(E E)$, total carbohydrates (CHO), neutral detergent fiber (NDF) and non fiber carbohydrates (NFC) of the concentrate, hay and ration

\begin{tabular}{lccr}
\hline Item & $\begin{array}{c}\text { Concentrado } \\
\text { Concentrate }\end{array}$ & $\begin{array}{c}\text { Feno } \\
\text { Hay }\end{array}$ & $\begin{array}{r}\text { Ração } \\
\text { Ration }\end{array}$ \\
\hline MS (\%)(DM) & 84,65 & 88,16 & 86,76 \\
$\mathrm{MO}^{1}(O M)$ & 96,05 & 94,11 & 94,89 \\
$\mathrm{~PB}^{1}(C P)$ & 22,16 & 6,90 & 13,00 \\
$\mathrm{EE}^{1}$ & 1,26 & 2,59 & 2,05 \\
$\mathrm{CHO}^{1}$ & 78,73 & 85,42 & 82,74 \\
$\mathrm{FDN}^{1}, 2(N D F)$ & 21,86 & 76,75 & 54,79 \\
$\mathrm{CNF}^{1}(N F C)$ & 56,87 & 8,67 & 27,65 \\
\hline
\end{tabular}

$1 \% \mathrm{MS}(\% \mathrm{DM})$.

${ }^{2}$ FDN corrigida para proteína e cinzas (NDF corrected for protein and ash).

perfazendo um total de seis amostras de abomaso, por animal em cada período. As coletas de omaso e de fezes foram feitas em dias alternados, utilizandose três animais, sempre às 8,12 e $16 \mathrm{~h}$, perfazendo um total de três amostras por animal em cada período.
Assim, os períodos de coletas de amostra de digesta de abomaso e fezes ou de omaso e fezes foram de seis dias cada. Posteriormente, foram processadas em moinho com peneira de $1 \mathrm{~mm}$ de porosidade, preparando-se uma amostra composta com base no peso seco para cada animal, armazenada em frascos de vidro para análises laboratoriais.

Os teores de matéria seca (MS), matéria orgânica $(\mathrm{MO})$, proteína bruta $(\mathrm{PB})$, extrato etéreo $(\mathrm{EE})$ e fibra em detergente neutro (FDN) foram quantificados conforme técnicas descritas por Silva \& Queiroz (2002). As determinações do cromo foram feitas nas amostras de abomaso, omaso e fezes, de acordo com o método proposto por Williams et al. (1962), citados por Silva \& Queiroz (2002).

O consumo de nutrientes digestíveis totais (cNDT) foi calculado pela fórmula descrita por Sniffen et al. (1992), na qual $\mathrm{cNDT}=(\mathrm{cPB}-\mathrm{PBf})+2,25(\mathrm{cEE}-$ $\mathrm{EEf})+(\mathrm{cCHO}-\mathrm{CHOf})$, em que cPB, cEE e cCHO significam consumos de $\mathrm{PB}$, EE e CHO, respectivamente, e $\mathrm{PBf}$, EEf e CHOf, teores de $\mathrm{PB}$, $\mathrm{EE}$ e $\mathrm{CHO}$ nas fezes.

Os dados foram avaliados por meio de análise de variância e de regressão, utilizando-se o programa SAEG - Sistema de Análises Estatísticas e Genéticas (UFV, 1999). As comparações entre as equações de regressão dos parâmetros avaliados (consumo e digestibilidade) foram realizadas de acordo com a metodologia recomendada por Regazzi (1996), para testar identidade de modelos.

\section{Resultados e Discussão}

Encontram-se na Tabela 3 os consumos médios diários de $\mathrm{CHO}, \mathrm{FDN}, \mathrm{CNF}$ e NDT, em quilogramas por dia ( $\mathrm{kg} / \mathrm{dia})$, equações de regressão (ER) e respectivos coeficientes de determinação, obtidos nos dias de coleta de digesta no abomaso (ABO) e omaso (OM), para as duas metodologias em conjunto, em função dos níveis de oferta. (NOF). O teste de identidade de modelos indicou não haver diferenças entre os consumos observados para ambas as metodologias de coleta de digesta, recomendando-se, portanto, o uso da equação conjunta.

Os consumos de CHO, FDN, CNF e NDT aumentaram linearmente com os níveis de ingestão, refletindo o mesmo comportamento observado para a ingestão de MS. Efeitos de níveis de ingestão sobre o consumo de FDN também foram encontrados por Firkins et al. (1986a, 1987). 
Tabela 3 - Médias, equações de regressão (ER) e coeficientes de determinação $\left(r^{2}\right)$ para os consumos de carboidratos totais $(\mathrm{CHO})$, fibra em detergente neutro (FDN), carboidratos não-fibrosos (CNF) e nutrientes digestíveis totais (NDT), em kg/dia, em função dos níveis de oferta (NOF) para as metodologias de coletas no abomaso $(\mathrm{ABO})$ e no omaso (OM)

Table 3 - Means, regression equations (RE) and coefficients of determination $\left(r^{2}\right)$ for the intakes of total carbohydrates (CHO), neutral detergent fiber (NDF), non fiber carbohydrates (NFC) and total digestible nutrients (TDN), $\mathrm{kg} /$ day, according to the intake levels (LEV), for the collection methodologies in the abomasum (ABO) and omasum (OM)

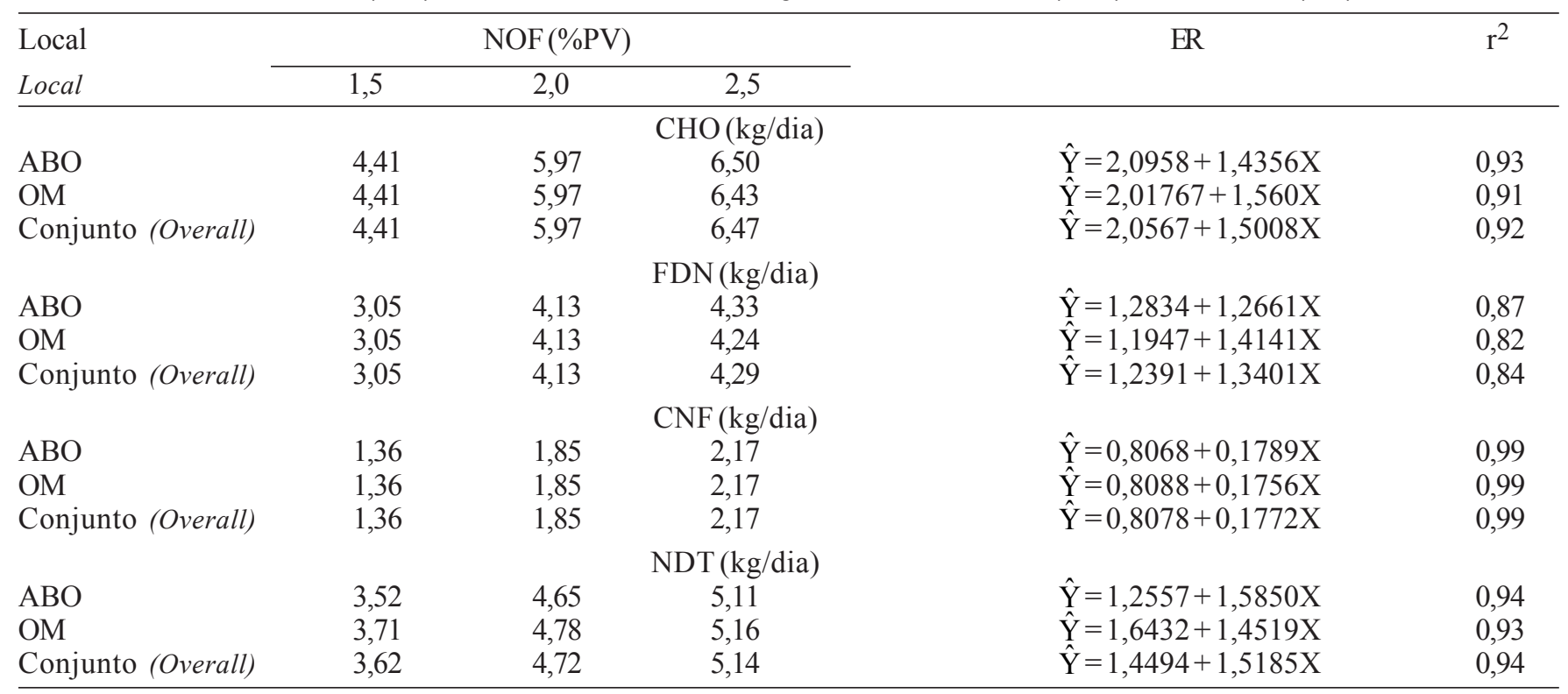

Na Tabela 4, são registrados os consumos médios diários de $\mathrm{CHO}, \mathrm{FDN}$ e CNF, em \% PV, equações de regressão (ER) e os respectivos coeficientes de determinação, obtidos para os dias de coleta de digesta no abomaso (ABO) e no omaso (OM) e para as duas metodologias em conjunto, em função dos níveis de oferta (NOF). O teste de identidade de modelos evidenciou não haver diferenças entre os consumos determinados ambas as metodologias de coleta de digesta. Portanto, pode-se recomendar o uso da equação conjunta, comum aos consumos.

Os consumos de CHO, FDN e CNF, em \% PV, aumentaram linearmente em função dos níveis de ingestão, em decorrência do aumento linear no consumo de MS.

Oconsumo médio de FDN de 1,09\% PV, no mais alto nível de oferta de alimentos, é próximo do valor de 1,2\% PV citado por Mertens (1992) como aquele em que vacas em lactação apresentaram ótimo consumo de MS.

Constam na Tabela 5 os resultados das digestibilidades total (DCHOTO), ruminal (DCHORU) e intestinais (DCHOIN) dos CHO e as equações de regressão (ER) obtidas para as duas metodologias de coleta de digesta isoladas e em conjunto, em função dos níveis de oferta (NOF). O teste de identidade de modelos, realizado para as equações de regressão relativas às digestibilidades total, ruminal e intestinais dos $\mathrm{CHO}$, em função dos níveis de oferta, indicou não existir diferenças entre as metodologias de coleta, recomendando-se, dessa forma, o uso da equação conjunta.

Embora o consumo de CHO tenha aumentado com os níveis de ingestão - reflexo do consumo de MS -, as digestibilidades total, ruminal e intestinais dos CHO não foram influenciadas pelos tratamentos, e apresentaram valores médios de 66,3; 91,3 e 8,7\%, respectivamente, para as equações conjuntas. Borges (2000), também em estudo com novilhas alimentadas em nível de mantença e ad libitum, relataram que a digestibilidade dos $\mathrm{CHO}$ não diferiu entre os tratamentos, com média de 65,5\%. Tibo et al. (2000), trabalhando com novilhos alimentados com dietas contendo diferentes proporções volumoso:concentrado, verificaram que, com o nível de $37,5 \%$ de concentrado na dieta, as digestibilidades total, ruminal e intestinal total foram, respectivamente, de 64,5; 87, 1 e 12,9\%. Dias et al. (2000) relataram, para esta mesma seqüência de digestibilidades, valores médios de 61,8 ; 89,0 e 11,0 , em estudo com a inclusão de níveis crescentes de concentrado ( 25 a $75 \%$ ). 
Tabela 4 - Médias, equações de regressão (ER) e coeficientes de determinação $\left(\mathrm{r}^{2}\right)$ para os consumos de carboidratos totais ( $\mathrm{CHO}$ ), fibra em detergente neutro (FDN) e carboidratos não-fibrosos (CNF), em \%PV, em função dos níveis de oferta (NOF) para as metodologias de coletas no abomaso (ABO) e no omaso (OM)

Table 4 - Means, regression equations (RE) and coefficients of determination $\left(r^{2}\right)$ for the intakes of total carbohydrates (CHO), neutral detergent fiber (NDF) and non fiber carbohydrates (NFC), \%LW, according to the intake levels (LEV), for the collection methodologies in the abomasum (ABO) and omasum (OM)

\begin{tabular}{|c|c|c|c|c|c|}
\hline \multirow{2}{*}{$\begin{array}{l}\text { Local } \\
\text { Local }\end{array}$} & \multicolumn{3}{|c|}{$\mathrm{NOF}(\% \mathrm{PV})$} & \multirow[t]{2}{*}{ ER } & \multirow[t]{2}{*}{$\mathrm{r}^{2}$} \\
\hline & 1,5 & 2,0 & 2,5 & & \\
\hline \multicolumn{6}{|c|}{$\mathrm{CHO}(\% \mathrm{PV})$} \\
\hline $\mathrm{ABO}$ & 1,13 & 1,52 & 1,66 & $\hat{\mathrm{Y}}=0,3838+0,5263 \mathrm{X}$ & 0,93 \\
\hline $\mathrm{OM}$ & 1,13 & 1,52 & 1,64 & $\hat{\mathrm{Y}}=0,4135+0,5085 \mathrm{X}$ & 0,92 \\
\hline Conjunto (Overall) & 1,13 & 1,52 & 1,65 & $\hat{\mathrm{Y}}=0,3987+0,5174 \mathrm{X}$ & 0,92 \\
\hline \multicolumn{6}{|c|}{ FDN $(\% \mathrm{PV})$} \\
\hline $\mathrm{ABO}$ & 0,78 & 1,05 & 1,10 & $\hat{\mathrm{Y}}=0,3362+0,3210 \mathrm{X}$ & 0,87 \\
\hline $\mathrm{OM}$ & 0,78 & 1,05 & 1,08 & $\hat{\mathrm{Y}}=0,3718+0,2997 \mathrm{X}$ & 0,83 \\
\hline \multicolumn{6}{|c|}{ CNF $(\% \mathrm{PV})$} \\
\hline $\mathrm{ABO}$ & 0,35 & 0,47 & 0,55 & $\hat{\mathrm{Y}}=0,0488+0,2046 \mathrm{X}$ & 0,99 \\
\hline $\mathrm{OM}$ & 0,35 & 0,47 & 0,56 & $\hat{\mathrm{Y}}=0,0479+0,2052 \mathrm{X}$ & 0,99 \\
\hline Conjunto (Overall) & 0,35 & 0,47 & 0,56 & $\hat{\mathrm{Y}}=0,0483+0,2049 \mathrm{X}$ & 0,99 \\
\hline
\end{tabular}

Tabela 5 - Médias e equações de regressão (ER) para as digestibilidades dos carboidratos totais (DCHOTO), no rúmen (DCHORU) e nos intestinos (DCHOIN), em função dos níveis de oferta (NOF) para as metodologias de coletas no abomaso (ABO) e no omaso (OM)

Table 5 - Means and regression equations (RE) for the total carbohydrates $(\mathrm{CHOD})$ digestibilities, in the rumen (CHODRU) and in the intestines (CHODIN), according to the intake levels (LEV), for the collection methodologies in the abomasum (ABO) and omasum (OM)

\begin{tabular}{|c|c|c|c|c|}
\hline Local & & $\mathrm{F}(\% \mathrm{P}$ & & ER \\
\hline Local & 1,5 & 2,0 & 2,5 & \\
\hline & & $\mathrm{CHOT}$ & & \\
\hline $\mathrm{ABO}$ & 66,01 & 65,53 & 65,49 & $\hat{\mathrm{Y}}=65,68$ \\
\hline $\mathrm{OM}$ & 68,14 & 66,19 & 66,10 & $\hat{\mathrm{Y}}=66,81$ \\
\hline Conjunto & 67,08 & 65,86 & 65,80 & $\hat{\mathrm{Y}}=66,25$ \\
\hline Overall & & 4 & & \\
\hline $\mathrm{ABO}$ & 91,18 & 91,41 & 91,83 & $\hat{\mathrm{Y}}=91,47$ \\
\hline $\mathrm{OM}$ & 90,32 & 91,04 & 91,87 & $\hat{\hat{Y}}=91,08$ \\
\hline Conjunto & 90,75 & 91,22 & 91,85 & $\hat{\hat{Y}}=91,27$ \\
\hline Overall & & & & \\
\hline & & $\mathrm{CHOI}$ & & \\
\hline $\mathrm{ABO}$ & 8,84 & 8,61 & 8,21 & $\hat{\mathrm{Y}}=8,55$ \\
\hline $\mathrm{OM}$ & 9,65 & 9,00 & 8,12 & $\hat{\hat{Y}}=8,92$ \\
\hline Conjunto & 9,25 & 8,81 & 8,17 & $\hat{\hat{Y}}=8,73$ \\
\hline Overall & & & & \\
\hline
\end{tabular}

$1 \%$ do total digerível (\% total digestible).

Embora não se tenha observado efeito dos tratamentos para a digestibilidade total de $\mathrm{CHO}$, houve redução numérica para os valores de digestibilidade, principalmente quando foram comparados os níveis de oferta de 1,5 e $2,5 \%$ PV.

R. Bras. Zootec., v.34, n.2, p.670-678, 2005
Valadares et al. (1997) citaram maior coeficiente de digestibilidade aparente total dos $\mathrm{CHO}$ para o nível de $14,5 \%$ em comparação ao de $7,0 \%$ PB $(68,7$ e $62,4 \%$, respectivamente).

Os resultados das digestibilidades total (DFDNTO), ruminal (DFDNRU) e intestinais (DFDNIN) da FDN, equações de regressão (ER) e respectivos coeficientes de determinação, obtidos para as duas metodologias de coleta de digesta isoladas, em função dos níveis de oferta (NOF), podem ser visualizados na Tabela 6 . O teste de identidade de modelos, realizado para as equações de regressão para a digestibilidade total da FDN, evidenciou diferenças quanto a este parâmetro, porém, para as digestibilidades ruminal e intestinais, indicou não existir diferenças entre as metodologias de coleta. Desse modo, pode-se recomendar o uso da equação conjunta somente para os locais de digestão da FDN.

Como não era esperado efeito do local de coleta sobre a digestibilidade total de FDN, esta diferença pode ter sido considerada ao acaso. Observou-se também que o local de coleta não afetou os sítios de digestão da FDN.

A digestibilidade total da FDN diminuiu linearmente com o aumento dos níveis de ingestão, o que provavelmente decorreu de uma taxa mais rápida de passagem, promovida pelo aumento de consumo deste nutriente. Firkins et al. (1987), Punia et al. (1988) e Woods et al. (1999) também encontraram digestibilidade total da FDN mais baixas em bovinos submetidos ao maior nível de ingestão. 
Tabela 6 - Médias, equações de regressão (ER) e coeficientes de determinação $\left(r^{2}\right)$ para as digestibilidades da fibra em detergente neutro total (DFDNTO), no rúmen (DFDNRU) e nos intestinos (DFDNIN), em função dos níveis de oferta (NOF) para as metodologias de coletas no abomaso (ABO) e no omaso (OM)

Table 6 - Means, regression equations (RE) and coefficients of digestibility $\left(r^{2}\right)$ for the total neutral detergent fiber digestibilities (NDFD), in the rumen (NDFDRU) and in the intestines (NDFDIN), according to the digestion levels (LEV), for the collection methodologies in the abomasum (ABO) and omasum (OM)

\begin{tabular}{lcccc}
\hline Local & \multicolumn{3}{c}{ NOF $(\% \mathrm{PV})$} & ER \\
\cline { 2 - 4 } & 1,5 & 2,0 & 2,5 & \\
ABO & 54,42 & 53,15 & DFDNTO & \\
OM & 59,16 & 55,12 & 50,81 & $\hat{\mathrm{Y}}=59,97-3,591 \mathrm{X}$ \\
& & & DFDNRU & $\hat{\mathrm{Y}}=67,36-5,750 \mathrm{X}$ \\
ABO & 93,24 & 93,87 & 96,29 & $\hat{\mathrm{Y}}=94,47$ \\
OM & 88,16 & 89,10 & 90,71 & $\hat{\mathrm{Y}}=89,32$ \\
Conjunto (Overall) & 90,70 & 91,49 & 93,50 & $\hat{\mathrm{Y}}=91,90$ \\
& & & DFDNIN & \\
ABO & 6,82 & 6,14 & 3,72 & $\hat{\mathrm{Y}}=5,56$ \\
OM & 11,80 & 10,89 & 9,31 & $\hat{\mathrm{Y}}=10,67$ \\
Conjunto (Overall) & 9,31 & 8,52 & 6,51 & $\hat{\mathrm{Y}}=8,11$ \\
\hline
\end{tabular}

$1 \%$ do total digerível (\% total digestible).

Os níveis de ingestão não influenciaram as digestibilidades ruminal e intestinais da FDN, que apresentaram valores médios de $91,9 \%$ e $8,1 \%$, respectivamente, para as equações conjuntas. Merchen et al. (1986) também não encontraram efeito do aumento do consumo (1,6 e 2,6\% PV) sobre a digestibilidade ruminal da FDN. O valor médio de $91,4 \%$ para a digestão ruminal está de acordo com a maioria dos resultados citados na literatura, o que era esperado, pois a FDN é utilizada, principalmente, no rúmen. Valadares et al. (1997), Carvalho et al. (1997), Ladeira et al. (1999) e Cardoso et al. (2000) relataram valores médios de 94,$0 ; 99,9 ; 96,4 ; 95,9 \%$, respectivamente.

Aumentando a ingestão de alimentos com forragens moídas ou picadas acima de $2 \%$ PV, Firkins et al. (1986b) observaram diminuição da extensão da digestão da FDN, tanto no trato total como no rúmen.

O valor médio de $8,1 \%$ para a digestibilidade intestinal da FDN concorda com a maioria dos resultados citados na literatura. Carvalho et al. (1997), Ladeira et al. (1999) e Cardoso et al. (2000) relataram valores médios de 0,$1 ; 3,6$ e $4,1 \%$, respectivamente, para este parâmetro, confirmando a quase totalidade da digestão da FDN no rúmen.

$\mathrm{Na}$ Tabela 7, encontram-se os resultados das digestibilidades total (DCNFTO), ruminal (DCNFRU) e intestinais (DCNFIN) dos CNF, equações de regressão (ER) e respectivos coeficientes de determinação, obtidos para as duas metodologias de coleta de digesta isoladas e em conjunto, em função dos níveis de oferta (NOF). O teste de identidade de modelos, realizado para as equações de regressão para a digestibilidade total de CNF, não indicou diferenças quanto a este parâmetro, enquanto, para as digestibilidades ruminal e intestinais, evidenciou diferenças entre as metodologias de coleta; portanto, não se pode recomendar o uso da equação conjunta para os locais de digestão dos CNF. Ressalta-se que, para quaisquer digestibilidades ruminais e intestinais avaliadas neste estudo, somente os CNF apresentaram diferenças quanto à metodologia de coleta no abomaso e omaso.

Não foi observado efeito dos níveis de ingestão para as digestibilidades totais dos CNF, com valor médio de 82,3 , para a equação conjunta. No entanto, Borges (2000), em estudo com novilhas alimentadas em nível de mantença e ad libitum, relataram que a digestibilidade dos CNF diferiu entre os tratamentos, com as respectivas médias: 92,2 e $89,7 \%$. Neste trabalho, o resultado foi um pouco inferior ao de Tibo et al. (2000), que encontraram coeficiente de digestibilidade total dos CNF de $88,4 \%$, quando o nível de concentrado da dieta foi de $37,5 \%$. Dias et al. (2000) relataram resultado médio do experimento de $91,6 \%$ para a digestão total dos CNF.

No presente estudo, utilizando a metodologia de coleta de digesta no omaso, foi observado aumento linear da digestibilidade ruminal dos CNF com o incremento dos níveis de ingestão, variando de 84,8 a 95,4\%. Zinn \& Owens (1983), ao estudarem o efeito de níveis crescentes de ingestão de MS em novilhos fistulados, encontraram aumento na digestão ruminal 
Tabela 7 - Médias, equações de regressão (ER) e coeficientes de determinação $\left(r^{2}\right)$ para as digestibilidades dos carboidratos não fibrosos total (DCNFTO), no rúmen (DCNFRU) e nos intestinos (DCNFIN) em função dos níveis de oferta (NOF) para as metodologias de coletas no abomaso (ABO) e no omaso (OM)

Table 7 - Means, regression equations (RE) and coefficients of digestibility $\left(r^{2}\right)$ for the total non fiber carbohydrates digestibilities (TNFCD), in the rumen (TNFCRU) and in the intestines (TNFCDIN), according to the digestion levels (LEV), for the collection methodologies in the abomasum (ABO) and omasum (OM)

\begin{tabular}{lcccc}
\hline Local & \multicolumn{3}{c}{ NOF $(\% \mathrm{PV})$} & ER \\
\cline { 2 - 3 } Local & 1,5 & 2,0 & 2,5 & \\
ABO & & & DCNFTO & \\
OM & 80,72 & 80,03 & 83,08 & $\hat{\mathrm{Y}}=81,28$ \\
Conjunto (Overall) & 83,89 & 81,37 & 84,42 & $\hat{\mathrm{Y}}=83,22$ \\
& 82,31 & 80,70 & 83,75 & $\hat{\mathrm{Y}}=82,25$ \\
ABO & & DCNFRU ${ }^{2}$ & \\
OM & 77,79 & 75,71 & 81,92 & $\hat{\mathrm{Y}}=78,47$ \\
& 84,83 & 90,82 & 95,40 & $\hat{\mathrm{Y}}=69,0434+0,6506 \mathrm{X}$ \\
ABO & & DCNFIN & \\
OM & & 18,16 & 0,80 \\
\hline
\end{tabular}

$1 \%$ do total digerível (\% total digestible).

do amido - um importante CNF em dietas de ruminantes. Contudo, quando foi usada a coleta no abomaso, não foi verificada influência do aumento do consumo sobre a digestão ruminal dos CNF, encontrando-se valor médio de $78,5 \%$, próximo ao resultado de Rennó (2004) (80,5\%), em estudo com dois níveis de proteína, e superior ao de Carvalho et al. (1997), de 63,3\%.

As digestibilidades intestinais dos CNF, obtidas pela metodologia de coleta no abomaso, não foram influenciadas pelos níveis de ingestão, encontrandose valor médio de $21,5 \%$, inferior ao de Tibo et al. (2000), que relataram média de $34,4 \%$. Com a metodologia de coleta no omaso, foi verificado comportamento linear decrescente, ou seja, o inverso do valor ocorrido para o valor ruminal.

Considerando todos os nutrientes, houve efeito do local de coleta somente para a digestão dos CNF. Isso não seria esperado, uma vez que os locais de digestão dos carboidratos totais e da FDN não foram influenciados pelo local de amostragem. Uma explicação para o efeito do local de coleta sobre a digestão ruminal e intestinal dos CNF, provavelmente, decorre da contaminação da FDN com cinzas e compostos nitrogenados. Destaca-se que os CNF são calculados pela diferença entre CHO e FDN. Rennó et al. (2002) relatou diferenças na digestibilidade total dos CNF, quando os mesmos foram calculados com e sem a correção da FDN para cinzas e compostos nitrogenados nas fezes e sobras, com valores de 84,8 e $88,7 \%$, respectivamente, mostrando que a contaminação da FDN pode influenciar a digestão dos CNF.

R. Bras. Zootec., v.34, n.2, p.670-678, 2005
Considerando que somente a digestibilidade total da FDN foi afetada pelo local de amostragem, essa diferença não seria esperada, em virtude de não haver diferença no consumo. Quanto aos locais de digestão, somente o dos CNF foi influenciado pelo local de amostragem, portanto, sugere-se o uso da coleta de omaso para estimar os locais de digestão dos nutrientes. Deve-se salientar que as coletas de digesta no omaso são menos invasivas e, então, podem ser recomendadas para substituir a coleta de digesta no abomaso, evitando a fistulação do animal neste compartimento gástrico.

\section{Conclusões}

A coleta de digesta abomasal pode ser substituída pela coleta de digesta omasal via fístula ruminal.

A coleta de digesta omasal é vantajosa, por tornar o processo menos invasivo e simplificar os estudos de digestão parcial.

\section{Literatura Citada}

AHVENJÄRVI, S.; VANHATALO, A.; HUHTANEN, P. et al. Determination of retículo-rumen and whole-stomach digestion in lactating cows by omasal canal or duodenal sampling. The British Journal of Nutrition, v.83, n.1, p.67-77, 2000.

ALLEN, M.S. Effects of diet on short-term regulation of feed intake by lactating dairy cows. Journal of Dairy Science, v.83, n.7, p.1598-1624, 2000.

ASH, R.W. Omasal-abomasal re-entrant cannullae for sheep. Journal Physiology, v.164, p.4, 1962.

BERCHIELLI, T.T.; RODRIGUEZ, N.M.; GONÇALVES, L.C. et al. Fluxo de nitrogênio duodenal e degradabilidade ruminal do nitrogênio da dieta estimado por meio de três marcadores 
microbianos. Revista Brasileira de Zootecnia, v.24, n.5, p.810-819, 1994.

BORGES A.L.C.C. Exigências nutricionais de proteína e energia de novilhas das raças Guzerá e Holandesa. Belo Horizonte, MG:UFMG, 2000. 90p. Tese (Doutorado em Ciência Animal) - Universidade Federal de Minas Gerais, 2000.

CARDOSO, R.C.; VALADARES FILHO, S.C.; COELHO DA SILVA, J.F. et al. Consumo e digestibilidades aparentes totais e parciais de rações contendo diferentes níveis de concentrado, em novilhos F1 Limousin x Nelore. Revista Brasileira de Zootecnia, v.29, n.6, p.1832-1843, 2000.

CARVALHO, A.U.; VALADARES FILHO, S.C.; COELHO DA SILVA, J.F. et al. Níveis de concentrados em dietas de zebuínos. 2. Coeficientes de digestibilidades aparentes parciais. Revista Brasileira de Zootecnia, v.26, n.5, p.996-1006, 1997.

DIAS, H.L.C.; VALADARES FILHO, S.C.; COELHO DA SILVA, J.F. et al. Consumo e digestões totais e parciais em novilhos $\mathrm{F}_{1}$ Limousin $\mathrm{x}$ Nelore alimentados com dietas contendo cinco níveis de concentrado, Revista Brasileira de Zootecnia, v.29, n.2, p.545-554, 2000.

FIRKINS, J.L.; BERGER, L.L.; MERCHEN, N.R. et al. Effects of forage particle size, level of feed intake and supplemental protein degradability on microbial protein synthesis and site of nutrient digestion in steers. Journal of Animal Science, v.62, n.4, p.1081-1094, 1986a.

FIRKINS, J.L.L.; BERGER, L.L.; MERCHEN, N.R. et al. Effects of feed intake and protein degradability on ruminal characteristics and site of digestion in steers. Journal of Dairy Science, v.69, n.8 p.2111-2123, 1986 b.

FIRKINS, J.L.; LEWIS, S.M.; MONGOMERY, L. et al. Effects of feed intake and dietary urea concentration on ruminal dilution rate and efficiency of bacterial growth in steers. Journal of Dairy Science, v.70, n.11, p.2312-2321, 1987.

FORBES, J.M. Voluntary food intake and diet selection in farm animals. Wallingford: CAB International, 1995. 532p.

HUHTANEN, P.G.; BROTZ, P.G.; SATTER, L.D. Omasal sampling technique for assessing fermentative digestion in the forestomach of dairy cows. Journal of Animal Science, v.75, n.5, p.1380-1392, 1997.

LADEIRA, M.M.; VALADARES FILHO, S.C.; COELHO DA SILVA, J.F. et al. Consumo e digestibilidades aparentes totais e parciais de dietas contendo diferentes níveis de concentrado, em novilhos Nelore. Revista Brasileira de Zootecnia, v.28, n.2, p.395-403, 1999.

MERCHEN, N.R.; FIRKINS, J.L.; BERGER, L.L. Effects of intake and forage on ruminal turnover rates, bacterial protein synthesis and duodenal amino acid flows in sheep, Journal of Animal Science, v.62, n.1, p.216-223, 1986.

MERTENS, D.R. Análise da fibra e sua utilização na avaliação e formulação de rações. In: SIMPÓSIO INTERNACIONAL DE RUMINANTES, REUNIÃO ANUAL DA SOCIEDADE BRASILEIRA DE ZOOTECNIA, 29., 1992, Lavras. Anais... Lavras: Sociedade Brasileira de Zootecnia, 1992. p.188-219.

NATIONAL RESEARCH COUNCIL - NRC. Ruminant nitrogen usage. Washington, D.C.: National Academy of Sciences, 1985. 158p.

NATIONAL RESEARCH COUNCIL - NRC. Nutrient requirements of dairy cattle. 6.ed. Washington, D.C.: National Academy of Sciences, 1989. 158p.

NATIONAL RESEARCH COUNCIL - NRC. Nutrient requirements of beef cattle. 7.ed. Washington, D.C.: National Academy of Sciences, 1996. 242p.

NATIONAL RESEARCH COUNCIL - NRC. Nutrient requirements of dairy cattle. 7.ed.rev. Washington, D.C.:
National Academy of Sciences, 2001. 381p.

PUNIA, B.S.; LEIBHOLZ, J.; FAICHNEY, G. Effects of level of intake and urea supplementation of alkali-treated straw on protozoal and bacterial nitrogen synthesis in the rumen and partition of digestion in cattle. American Journal Agricultural Research, v.39, n.1, p.1181-1194, 1988.

RENNÓ, L.N.; VALADARES FILHO, S.C.; PAULINO, M.F. et al. Indicadores interno ou externo e efeito da contaminação da fibra em detergente neutro sobre a digestibilidade aparente total em novilhos. In: REUNIÃO ANUAL DA SOCIEDADE BRASILEIRA DE ZOOTECNIA, 39., 2002, Recife. Anais... Recife: Sociedade Brasileira de Zootecnia, 2002.

RENNÓ, L.N.; VALADARES FILHO, S.C.; VALADARES, R.F. et al. Níveis de proteína na ração de novilhos de quatro grupos genéticos: Digestibilidade aparente parcial. In: REUNIÃO DA SOCIEDADE BRASILEIRA DE ZOOTECNIA, 41., 2004, Campo Grande, Anais... Campo Grande: Sociedade Brasileira de Zootecnia, 2004. CD ROOM.

REGAZZI, J.A. Teste para verificar a identidade de modelos de regressão. Pesquisa Agropecuária Brasileira, v.31, n.1, p.1-17, 1996.

RUPP, G.P.; KREIKEMEIER, K.K.; PERINO, L.J. et al. Measurement of volatile fatty acid disappearance and fluid flux across the abomasum of cattle utilizing an improved omasal cannulation technique. American Journal of Veterinary Research, v.55, n.4, p.522-529,1994.

RUSSELL, J.B.; O'CONNOR, J.D.; FOX, D.G. et al. A net carbohydrate and protein system for evaluating cattle diets: I. Ruminal fermentation. Journal of Animal Science, v.70, n.11, p.3551-3561, 1992.

SILVA, D.J.; QUEIROZ, A.C. Análise de alimentos (Métodos químicos e biológicos). Viçosa, MG: Universidade Federal de Viçosa, 2002. 235p.

SNIFFEN, C.J.; O`CONNOR, J.D.; Van SOEST, P.J. et al. A net carbohydrate and protein system for evaluation cattle diets: II. Carbohydrate and protein availability. Journal of Animal Science, v.70, n.11, p.3562-3577, 1992.

TIBO, G.C.; VALADARES FILHO, S.C.; VALADARES, R.F.D. et al. Níveis de concentrado em dietas de novilhos mestiços F1 Simental x Nelore 1. Consumo e digestibilidades. Revista Brasileira de Zootecnia, v.29, n.3, p.910-919, 2000.

TITGEMEYER, E.C. Design and interpretation of nutrient digestion studies. Journal of Animal Science, v.75, n.8, p.2235-2247, 1997.

TYRREL, H.F.; MOE, P.W. Effect of intake on digestive efficiency. Journal of Dairy Science, v.58, n.8, p.1151-1163, 1975.

UNIVERSIDADE FEDERAL DE VIÇOSA. SAEG - Sistema de análises estatísticas e genéticas Viçosa, MG: UFV. (Apostila), 1999.

VALADARES, R.F.D.; GONÇALVES, L.C.; SAMPAIO, I.B. et al. Níveis de proteína em dietas de bovinos. 1. Consumo e digestibilidades aparentes totais e parciais. Revista Brasileira de Zootecnia, v.26, n.6, p.1252-1258,1997.

WOODS, V.W.; MOLONEY, A.P.; MULLIGAN F.J. et al. The effect of animal species (cattle or sheep) and level of intake by cattle on in vivo digestibility of concentrate ingredients. Animal Feed Science and Technology, v.80, n.1, p.35-190, 1999.

ZINN, R.A.; OWENS, F.N. Influence of feed intake level on site of digestion in steers fed a high concentrate diet. Journal of Animal Science, v.56, n.2, p.471-475, 1983.

Recebido em: 19/09/03 Aceito em: 05/11/04 